\title{
Priming and recognition in ECT-induced amnesia
}

\author{
JENNIFER DORFMAN \\ University of Memphis, Memphis, Tennessee \\ JOHN F. KIHLSTROM \\ Yale University, New Haven, Connecticut \\ RANDALL C. CORK \\ Louisiana State University Medical Center, New Orleans, Louisiana \\ and \\ JOHN MISIASZEK \\ University of Arizona College of Medicine, Tucson, Arizona
}

\begin{abstract}
Priming and recognition were tested in patients receiving electroconvulsive therapy (ECT) for treatment of a psychiatric disorder. Patients studied a list of words just prior to ECT and then received memory tests for those words after recovering from ECT. Stem-cued recall was poor (retrograde amnesia), but priming on word-stem completion was preserved. Recognition was poor on a "high-criterion" test requiring a retrieval-based judgment but partially intact on a "low-criterion" test requiring a familiarity-based judgment. The results support the familiarity-retrieval distinction in two-component theories of recognition and suggest that signal detection measures of sensitivity are not wholly independent of response criteria.
\end{abstract}

The primary side effects of electroconvulsive therapy (ECT) are a retrograde amnesia covering the period immediately before treatment is administered and an anterograde amnesia covering the period immediately afterwards. This memory impairment is similar to that observed in the organic amnesic syndrome associated with lesions to the medial temporal lobes and diencephalic midline (Squire, 1984; Williams, 1966). Like the amnesia produced by traumatic head injury, ECT-induced amnesia is transient, resolving within a year and leaving little residual impairment aside from a lacuna surrounding the period of treatment (Squire, 1992a; Squire, Slater, \& Chace, 1975).

There is some evidence to suggest that the amnesia produced by ECT may spare certain forms of learning and memory. For example, patients taught a perceptual (mirrorreading) skill early in a course of ECT show improved performance of that skill after ECT, despite little recollection of having performed it previously (Squire, Cohen, \& Zouzounis, 1984). Similarly, patients who are unable to remember a list of words presented immedi-

Portions of this research were presented at the Inaugural Meeting of the Cognitive Neuroscience Society, San Francisco, March, 1994, and at the Sixth Annual Convention of the American Psychological Society, Washington, DC, July, 1994. This research was supported by a National Institute of Mental Health (NIMH) postdoctoral fellowship to J.D. (MH10042), and in part by NIMH Grant MH35856 to J.F.K. We thank two anonymous reviewers for their helpful comments on an earlier version of this article. R.C.C. is in the Department of Anesthesiology at the LSU Medical Center; J.M. is in the Department of Psychiatry at the Arizona College of Medicine. Correspondence concerning this article should be addressed to J. Dorfman, Department of Psychology, University of Memphis, Memphis, TN 38152. ately after a single ECT treatment nevertheless show priming for those words on a word-stem completion test (Graf, Squire, \& Mandler, 1984; Squire, Shimamura, \& Graf, 1985). The kind of memory that patients express on these tasks is known as implicit memory-a change in task performance attributable to some prior event that may occur in the absence of explicit recollection of that event. Dissociations between implicit memory and explicit recollection are commonly demonstrated in patients with the organic amnesic syndrome, in subjects with functional amnesia, and in nonamnesic subjects following a variety of experimental manipulations (for reviews, see Schacter, 1987; Schacter, Chiu, \& Ochsner, 1993; Schacter \& Kihlstrom, 1989). Such dissociations suggest a distinction between two kinds of memory processes or systems - one involving deliberate retrieval of elaborative, declarative, or episodic information and requiring the integrity of the brain regions affected in amnesia; and one based on automatic access to integrative, nondeclarative, or perceptual information and independent of those brain regions (e.g., Graf \& Mandler, 1984; Jacoby, 1983; Mandler, 1989; Schacter, 1990; Squire, 1992b; Tulving \& Schacter, 1990).

The purpose of the present study was to examine implicit memory in ECT-induced retrograde amnesia, and its contribution to explicit recollection. In particular, we were interested in the acute retrograde effects produced by an individual treatment in a course of (bilateral) ECT. The effects of a single electroconvulsive stimulus on explicit memory have been well documented in studies of both humans and animals. In humans, explicit memory impairments have been shown to occur for both verbal 
and nonverbal materials, presented up to $1 \mathrm{~h}$ prior to treatment, and tested up to $24 \mathrm{~h}$ after treatment. This amnesia exhibits a temporal gradient, whereby events closer to treatment are more greatly affected than more remote events - suggesting a disruption of the neural processes responsible for the consolidation of memory traces (McGaugh \& Herz, 1972; Squire, Cohen, \& Nadel, 1984; but see Miller \& Marlin, 1979, for a different view).

There has been little work investigating implicit memory for information presented prior to an individual ECT treatment. Suggestive evidence for the preservation of implicit memory is available from an early study conducted by Williams (1950a). In that study, patients were presented with a series of degraded ink blots that progressively represented a particular object (e.g., an elephant). After ECT, patients showed little memory for the ink blots, but nevertheless gave responses similar to the ones given pre-ECT. For example, one patient who had called an elephant a polar bear again gave that response, and, moreover, gave it earlier in the sequence of stimuli. In a follow-up study, Williams (1950b) showed that patients were better at identifying degraded pictures when they had seen intact pictures prior to ECT.

In the present study, we examined whether patients show priming for information presented just prior to ECT, in the form of completing word stems with previously exposed words. Since it has been demonstrated that patients can show word-stem completion priming for information covered by anterograde amnesia (Graf et al., 1984; Squire et al., 1985), we reasoned that a similar effect should be evident for retrograde amnesia. We compared word-stem completion with explicit stemcued recall.

A second goal of the study was to test the hypothesis that the process underlying priming can serve as a basis for recognition in amnesia. According to dual-process theories of recognition (e.g., Mandler, 1980; see also Atkinson \& Juola, 1973; Jacoby \& Dallas, 1981), two mental processes contribute to recognition judgmentsa context-independent process based on activation of perceptual or intrastructural aspects of an event; and a context-sensitive process dependent on retrieval of relational/conceptual information. The former underlies the familiarity component of recognition-as exemplified by the common experience of encountering someone on the street, recognizing him/her as familiar, but being unable to place the source of that familiarity. This process is also thought to mediate priming. The second process is important in recovering information about when and where an object or event was experienced - for example, knowing that the person on the street is your barber and that you last saw him a month ago.

Evidence for a common process in priming and recognition is apparent in many domains. For example, amnesic patients often exhibit partially intact recognition, despite showing very poor recall (e.g., Hirst \& Volpe, 1982; Hirst et al., 1986; Huppert \& Piercy, 1977; but see Haist, Shimamura, \& Squire, 1992, for a different view). Moreover, the rate of decay in recognition mirrors that of priming (word-stem completion; Graf et al., 1984). There is also neurophysiological evidence suggesting that amnesics show recognition based on familiarity, but not conscious retrieval (Smith \& Halgren, 1989). In normal subjects, variables such as repetition and retention interval have been shown to affect priming (word-stem completion and perceptual identification) and recognition in a similar fashion (e.g., Dorfman \& Mandler, 1994; Graf \& Mandler, 1984; Jacoby \& Dallas, 1981). Other variables have been shown to differentially affect the familiarity and retrieval components of recognition-for example, judgments of knowing versus judgments of remembering (e.g., Gardiner, 1988).

To examine whether familiarity can support recognition in ECT-induced amnesia, we used two kinds of (yes-no) recognition tests. In a high-criterion test, subjects were instructed to respond "yes" to an item only if they were certain they had seen it on the study list. This task was meant to encourage a retrieval-based strategy. In a low-criterion test, subjects were told to say "yes" to a word even if they were not sure they had seen that word. This task was intended to tap into a familiaritybased process.

\section{METHOD}

Just prior to ECT, patients rated a list of study words according to likeability. After ECT, patients were given tests of stem-cued recall, stem completion, high-criterion recognition, and low-criterion recognition. In order to eliminate test effects, each test targeted different subsets of study items. A control group completed the study and test phases without intervening ECT.

\section{Subjects}

The treatment group consisted of 5 men and 3 women who were psychiatric patients at two local hospitals. Seven patients were prescribed ECT for relief of a major affective disorder; the remaining patient received ECT for absessive-compulsive disorder. The average age of the patients was 62.1 years, and the average education level was 11.6 years. Four patients had received prior ECT treatment, from 6 months to 30 years previously

The control group consisted of 4 men and 4 women who were matched on age and education level with the treatment group. The average age was 61.0 years, and the average education level was 12.9 years. These subjects were recruited from the Tucson community.

For each group, half the subjects received the stem completion and low-criterion recognition tests followed by the stem-cued recall and high-criterion recognition tests. The other half received the tests in the reverse order.

\section{Materials}

Two sets of materials were constructed from a pool of 56 words. Twenty-eight words were selected for the stem completion and stemcued recall tests. The second set of 28 words was selected for the lowand high-criterion recognition tests.

Items for the first test set were culled from the stem completion norms in Graf and Williams (1987). These words were divided into two lists of 14 words, matched according to base completion rate and frequency of occurrence. The average base rate was .11, and the average frequency (Kučera \& Francis, 1967) was 49 per million. One list served as items for the stem completion test, and the other list served as items for the stem-cued recall test. These lists were counterbalanced across subjects, in such a way that half the subjects received the reverse assignments. Each list of 14 items was further divided into groups of 7 items, equated on base completion rate and frequency. Half of these items were presented on the study list; the other half were used 
to assess baseline performance in the case of the stem completion test and as fillers in the case of the stem-cued recall test.

The recognition test set consisted of items of the same general frequency range as the stem completion/stem-cued recall test set. Two lists of 14 items were constructed, matched on frequency 46 per million). Half of the items on each list were designated as study list items and half were designated as nonstudied distractors.

The study list consisted of 28 words both preceded and followed by three buffer words. The stem completion and stem-cued recall test lists consisted of the stems of the studied and nonstudied items, with two practice items at the beginning of each list. The recognition test lists consisted of the studied and nonstudied items preceded by two practice items.

\section{Administration of Treatment and Procedure}

ECT was administered three times per week on alternate days. A barbiturate anesthetic (methohexital, $50-70 \mathrm{mg}$ ) and muscle relaxant (succinylcholine, $60-120 \mathrm{mg}$ ) were given intravenously. All patients received treatment with a MECTA device. The stimulus parameters were $80-90 \mathrm{~Hz}$ pulse frequency, 1.0-1.2 pulse width, $4.00-9.75 \mathrm{stim}-$ ulus setting, $1.0-3.3 \mathrm{sec}$ stimulus duration, and $.8 \mathrm{amp}$ current. Electrode placement was bitemporal. In all the cases in which testing occurred, the current produced a clinically viable seizure, confirmed by EEG monitoring.

Although acute retrograde effects should be evident regardless of the treatment in which patients are tested, previous studies have often tested patients in the middle of a course of ECT. Accordingly, we tested patients before and after their fourth, fifth, or sixth treatment. The learning session was administered 10-30 min prior to treatment, depending on the conditions of the particular hospital. Patients were given the list of study words and asked to rate how much they liked each word on a scale of 1 to 5 . The order of the words was randomly determined for each patient. Patients' responses were recorded by the examiner. Patients were allowed as much time as needed to provide a response, but typically responded within $5-10 \mathrm{sec}$.

The memory tests were administered approximately $50-60 \mathrm{~min}$ posttreatment, after postictal confusion had subsided. In the stemcued recall test, patients were asked to respond with a word that was on the presentation list. Patients were discouraged from guessing: they were told only to respond with words they were relatively sure were on the list. In the stem completion test, patients were instructed to complete each item with "the first word that comes to mind." They were told to respond as quickly as possible and not to give any proper nouns. In the high-criterion recognition test, patients were instructed to respond "yes" only if they were relatively certain a word had appeared on the presentation list. They were told: "If you're fairly sure you saw the word, then you should say 'yes.' If you're not so sure or don't think you saw the word, you should say 'no.' "In the low-criterion recognition test, patients were instructed to respond "yes" even if they were not sure they had seen the word. They were told: "If you think you might have seen the word, or if it seems familiar to you at all, then you should say 'yes.' If it doesn't seem familiar to you, you should say "no." It was emphasized that subjects respond as quickly as possible, according to their first impression. All the tests were subject paced.

The procedure was the same for the control subjects, except that ECT was not administered between the study and test phases. During the delay, subjects participated in an unrelated study with nonverbal stimulus materials. Controls were matched to patients in terms of the study-test interval.

\section{RESULTS}

\section{Stem-Cued Recall and Stem Completion}

Figure 1 summarizes the stem-cued recall and stem completion data. The top panel shows the proportion of studied items correctly recalled by ECT patients and controls. Virtually no nonstudied items were recalled. The bottom panel shows the proportion of studied and nonstudied items given as stem completions. An analy- sis of the cued recall data revealed a dense amnesia in the ECT group. ECT patients recalled only .05 of the studied items, in contrast to .45 by the control subjects $[t(14)=5.55, p<.001]$.

Despite poor explicit memory, patients showed priming on the stem completion task. The proportion of studied items completed was .30 , in contrast to a base rate of .04 for nonstudied items, yielding a priming effect of .26 $[t(7)=4.68, p<.01]$. Control subjects correctly completed .23 of the studied items, versus a base rate of .07 , for a priming effect of .16 $[t(7)=2.55, p<.05]$. The magnitude of priming did not differ significantly for the ECT and control groups $[t(14)=1.27]$.

\section{Recognition}

The recognition data are depicted in Figure 2. The top panel shows the proportion of "yes" (old) responses to studied and nonstudied items (hits and false alarms) for the high- and low-criterion tests. The bottom panel shows the data represented in terms of $d^{\prime}$. The $d^{\prime}$ analysis was based on the hit and false alarm rates for individual subjects. A constant of .999 or .001 was used to estimate hit and false alarm rates of 1.00 and .00 , respectively. An analysis using the statistic $A_{z}$ (area under the ROC curve; Swets \& Pickett, 1982) yielded a similar pattern of results. $A_{z}$ does not require a correction for
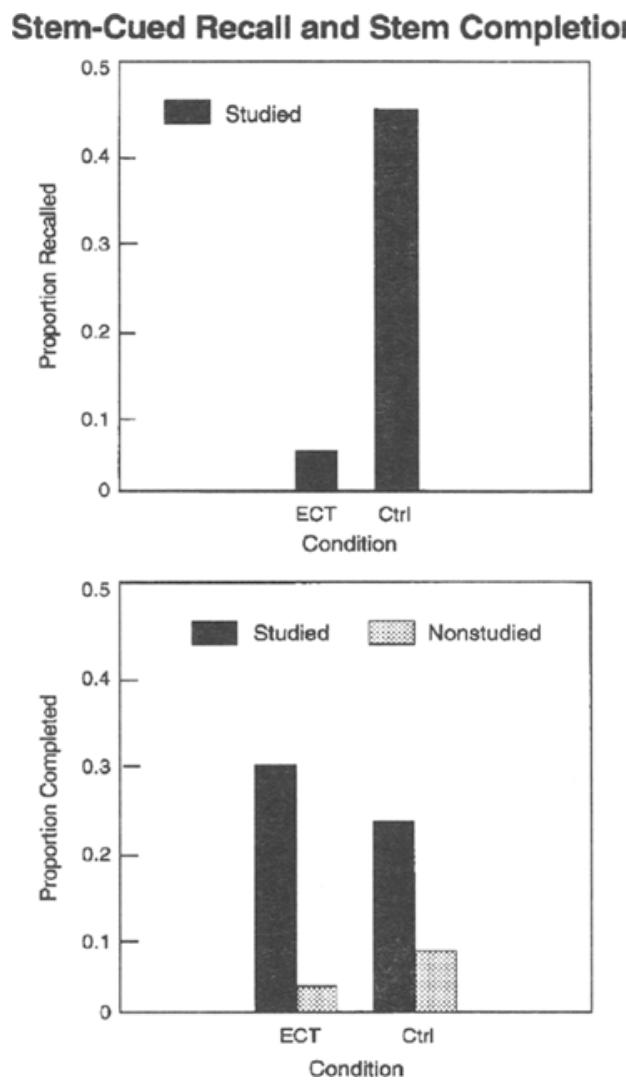

Figure 1. Proportion of studied and nonstudied items recalled or completed. 

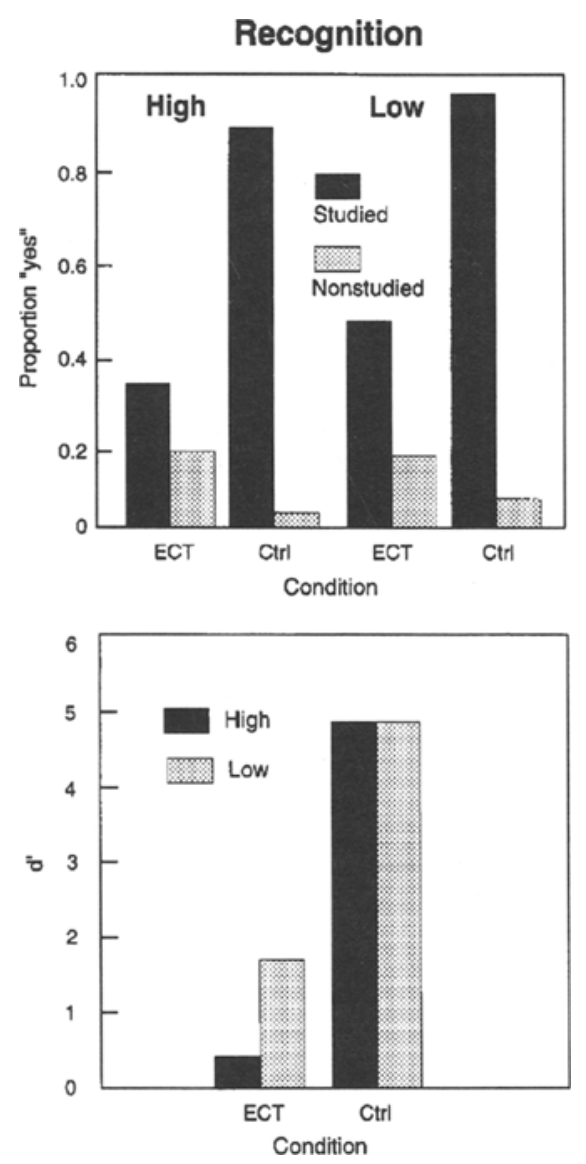

Figure 2. Proportion of studied and nonstudied items identified as old, and $d^{\prime}$ scores, under two criteria.

hit and false alarm rates of 1.00 and .00 , and it is often the preferred measure of sensitivity in applications of signal detection theory (Swets, 1988). Whereas $d^{\prime}$ may take on infinite values when hit and false alarm rates are 1.00 or $.00, A_{z}$ is always finite. ${ }^{1}$

Analysis of the data confirmed that ECT patients performed better on the low-criterion test than on the highcriterion test. The hit rate was greater for the low-criterion test (.48) than for the high-criterion test $(.34)[t(7)=3.77$, $p<.01]$, but the false alarm rate did not differ across the two tests $(.18$ vs. .20) $[t(7)=-.29]$. An analysis in terms of $d^{\prime}$ confirmed a difference in discriminability $[t(7)=$ $2.88, p<.05$ ], with $d^{\prime}$ higher for the low-criterion test (1.70) than for the high-criterion test (.41).

For control subjects, both the hit and false alarm rates were numerically (but not significantly) greater for the low- than for the high-criterion test. The hit rate was .97 for the low-criterion test, in contrast to .91 for the highcriterion test $[t(7)=1.17]$. The false alarm rate was .07 for the low-criterion test, as opposed to .02 for the highcriterion test $[t(7)=1.15]$. In terms of $d^{\prime}$, this translated into 4.86 for both tests. Given likely ceiling effects in the hit rate for the low-criterion test, however, no definitive conclusions may be made regarding changes in discrim- inability for control subjects. The important point for our present purposes is simply that discriminability changes can in fact occur when subjects shift their criterion for recognition.

Overall, ECT patients showed poorer recognition (discriminability) than did control subjects. Patients exhibited a dense amnesia on the high-criterion test (4.86 vs. $.41)[t(14)=7.66, p<.001]$. They showed considerably better, but still impaired, recognition on the low-criterion test $(4.86$ vs. 1.70$)[t(14)=4.17, p<.01]$.

\section{DISCUSSION}

The results of the present study confirm that priming occurs for information covered by ECT-induced retrograde amnesia and, moreover, suggest that the process underlying priming can support some degree of recognition in amnesia. Following ECT, patients give previously studied words as responses on an implicit stem completion test, despite showing poor explicit memory for those words on a stem-cued recall test. In addition, patients show partially intact recognition when they are given instructions encouraging a familiarity-based response (lowcriterion test), but not a retrieval-based response (high-criterion test).

The present results extend previous reports of spared implicit memory for information presented prior to ECT. Squire et al. (1984) showed that patients who learned a perceptual (mirror-reading) skill early in a course of ECT exhibited facilitation of that skill several weeks after the completion of ECT. This facilitation occurred despite poor explicit memory for the learning sessions. In an early study done by Williams (1950a), patients showed preserved responses to ink blot stimuli seen just prior to a single treatment, despite being unable to recall those responses or the stimuli that elicited them (see also Williams, 1950b). Similar effects have been observed for the anterograde component of amnesia: patients show priming of word completions for items studied just after ECT, despite little recollection of those items (Graf et al., 1984; Squire et al., 1985).

The dissociation between explicit and implicit memory, observed in a variety of subject populations, suggests a distinction between two kinds of memory processes or systems - one deliberate and based on retrieval of a prior learning episode, and the other automatic and not requiring conscious recollection. These processes or systems have variously been referred to as elaboration and activation/integration (Graf \& Mandler, 1984; Mandler, 1989), conceptually driven and data-driven processing (Jacoby, 1983; Roediger \& Blaxton, 1987), declarative and nondeclarative memory (Squire, 1992b), and episodic and perceptual memory (Schacter, 1990; Tulving \& Schacter, 1990). Regardless of the nomenclature, studies such as the present one suggest that implicit effects rely on brain regions other than the medial temporal and diencephalic structures thought to be affected in amnesia.

Our data indicate, further, that the process or system underlying implicit memory can support some degree of recognition. The finding of partially intact recognition on the low-criterion test is consistent with dual process theories (see, e.g., Mandler, 1980; see also Atkinson \& Juola, 1973; Jacoby \& Dallas, 1981), which hold that recognition can be mediated by the same activation-based process that underlies priming. Also in line with such theories, previous studies have shown that amnesic patients often show above-chance recognition, despite very poor recall (e.g., Hirst et al., 1986; Hirst \& Volpe, 1982; Huppert \& Piercy, 1977; but see Haist et al., 1992)..$^{2}$ A study using event-related potential methodology, moreover, provided evidence that the familiarity component of recognition is intact in amnesic patients, despite little evidence of retrieval (Smith \& Halgren, 1989). Support for a dualprocess model is also available from numerous studies of normal subjects (e.g., Dorfman \& Mandler, 1994; Graf \& Mandler, 1984; Jacoby \& Dallas, 1981).

It should be noted that the present results are inconsistent with a previous investigation of priming and recognition in ECT-induced anterograde amnesia. Squire et al. (1985) found that priming of wordstem completions was intact $45 \mathrm{~min}$ after ECT, despite chance-level recognition. However, we do not know what criterion the patients in their 
study used to make their recognition judgments. It is possible that these patients based their responses primarily on retrieval, which requires more than the activation underlying priming and familiarity The present study suggests that it might be more informative to test recognition by using instructions that encourage a familiarity-based response (see Gardiner, 1988, for similar findings with normal subjects).

Our results also have implications for the generality of a signal detection model as an account of recognition phenomena. According to such models (see, e.g., Green \& Swets, 1966), a change in instructions is assumed to have an equivalent effect on both hits and false alarmsthat is, an effect on the decision criterion beta, not on $d^{\prime}$. The fact that the hit rate for ECT patients increased across a change in instructions, while the false alarm rate did not, is contrary to this assumption. This suggests that familiarity and retrieval may tap memory processes or systems that have different operating characteristics.

\section{REFERENCES}

AtKinson, R. C., \& Juola, J. F. (1973). Factors influencing speed and accuracy of word recognition. In S. Kornblum (Ed.), Attention and performance IV (pp. 583-612). New York: Academic Press.

DORFMAN, J., \& MANDLER, G. (1994). Implicit and explicit forgetting: When is gist remembered? Quarterly Journal of Experimental Psychology, 47A, 651-672.

GARDINER, J. M. (1988). Functional aspects of recollective experience. Memory \& Cognition, 16, 309-313.

GRAF, P., \& MANDLER, G. (1984). Activation makes words more accessible but not necessarily more retrievable. Journal of Verbal Learning \& Verbal Behavior, 23, 553-568

Graf, P., Squire, L. R., \& MANDLeR, G. (1984). The information that amnesic patients do not forget. Journal of Experimental Psychology: Learning, Memory, and Cognition, 10, 164-178.

GraF, P., \& Williams, D. (1987). Completion norms for 40 three-letter word stems. Behavior Research Methods, Instruments, \& Computers, 19, 422-445.

GreEn, D. M., \& Swets, J. A. (1966). Signal detection theory and psychophysics. New York: Wiley.

Haist, F., Shimamura, A. P., \& SQuire, L. R. (1992). On the relationship between recall and recognition memory. Journal of Experimental Psychology: Learning, Memory, \& Cognition, 18, 691-702.

Hirst, W., Johnson, M. K., Kim, J. K., Phelps, E. A., Risse, G., \& VOLPE, B. T. (1986). Recognition and recall in amnesics. Journal of Experimental Psychology: Learning. Memory, \& Cognition, 12, 445-451.

HiRST, W., \& VolPE, B. T. (1982). Temporal order judgments with amnesia. Brain \& Cognition, 1, 294-306.

HUPPERT, F. A., \& PIERCY, M. (1977). Recognition memory in amnesic patients: A defect in acquisition? Neuropsychologia, 15, 643-652.

$J_{A C O B Y}$, L. L. (1983). Remembering the data: Analyzing interactive processes in reading. Journal of Verbal Learning \& Verbal Behavior, 22, 485-508.

JACOBY, L. L., \& DALLAS, M. (1981). On the relationship between autobiographical memory and perceptual learning. Journal of Experimental Psychology: General, 110, 306-340.

KuČERA, H., \& FRANCIS, W. N. (1967). Computational analysis of present-day American English. Providence, RI: Brown University Press.

MANDLER, G. (1980). Recognizing: The judgment of previous occurrence. Psychological Review, 87, 252-271.

MANDLER, G. (1989). Memory: Conscious and unconscious. In P. R. Solomon, G. R. Goethals, C. M. Kelley, \& B. R. Stephens (Eds.), Memory: An interdisciplinary approach (pp. 84-106). New York: Springer-Verlag.

MCGAUGH, J. L., \& HeRZ, M. J. (1972). Memory consolidation. San Francisco: Albion.

Miller, R. R., \& MARLIN, N. A. (1979). Amnesia following electroconvulsive shock. In J. F. Kihlstrom \& F. J. Evans (Eds.), Functional disorders of memory (pp. 143-178). Hillsdale, NJ: Erlbaum.

ROEDIGER, H. L. III., \& BLAXTON, T. A. (1987). Effects of varying modality, surface features, and retention interval on priming in wordfragment completion. Memory \& Cognition, 15, 379-388.
SCHACTER, D. L. (1987). Implicit memory: History and current status. Journal of Experimental Psychology: Learning, Memory, \& Cognition, 13, 501-518.

SCHACTER, D. L. (1990). Perceptual representation systems and implicit memory: Toward a resolution of the multiple memory systems debate. In A. Diamond (Ed.), The development and neural bases of higher cognitive functions (Annals of the New York Academy of Sciences, Vol. 608, pp. 543-571). New York: New York Academy of Sciences.

SCHACTER, D. L., ChIU, C. P., \& OCHSNER, K. N. (1993). Implicit memory: A selective review. Annual Review of Neuroscience, 16, 159-182.

SChACTER, D. L., \& Kinlstrom, J. F. (1989). Functional amnesia. In F. Boller \& J. Graffman (Eds.), Handbook of neuropsychology (Vol. 3, pp. 209-231). Amsterdam: Elsevier.

SMITH, M. E., \& Halgren, E. (1989). Dissociation of recognition memory components following temporal lobe lesions. Journal of Experimental Psychology: Learning, Memory, \& Cognition, 15, 50-60.

SQUIRE, L. R. (1984). ECT and memory dysfunction. In B. Lerer, R. D. Weiner, \& R. H. Belmaker (Eds.), ECT: Basic mechanisms (pp. 156163). London: John Libbey.

SQUIRE, L. R. (1992a). Electroconvulsive therapy and memory loss. In L. R. Squire (Ed.), Encyclopedia of learning and memory. New York: Macmillan

SQuiRe, L. R. (1992b). Memory and the hippocampus: A synthesis from findings with rats, monkeys, and humans. Psychological Review, 99, 195-231.

SQuire, L. R., COHEN, N. J., \& NADEL, L. (1984). The medial temporal region and memory consolidation: A new hypothesis. In H. Weingartner \& E. Parker (Eds.), Memory consolidation (pp. 185210). Hillsdale, NJ: Erlbaum.

Squire, L. R., Cohen, N. J., \& Zouzounis, J. A. (1984). Retrograde amnesia: Sparing of a recently acquired skill. Neuropsychologia, 22, 145-152.

SQUiRe, L. R., Shimamura, A. P., \& GRaF, P. (1985). Independence of recognition memory and priming effects: A neuropsychological analysis. Journal of Experimental Psychology: Learning, Memory, \& Cognition, 11, 37-44.

SQuire, L. R., Slater, P. C., \& ChaCe, P. M. (1975). Retrograde amnesia: Temporal gradient in very long term memory following electroconvulsive therapy. Science, 187, 77-79.

SwETs, J. A. (1988). Measuring the accuracy of diagnostic systems. Science, 240, 1285-1293

SWETS, J. A., \& PiCKeTT, R. M. (1982). Evaluation of diagnostic systems: Methods from signal detection theory. New York: Academic Press.

Tulving, E., \& SCHaCter, D. L. (1990). Priming and human memory systems. Science, 247, 301-306.

WiLliams, M. (1950a). Memory studies in electric convulsion therapy. Journal of Neurology, Neurosurgery, \& Psychiatry, 13, 30-35.

Williams, M. (1950b). Memory studies in electric convulsion therapy II: The persistence of verbal response patterns. Journal of Neurology, Neurosurgery, \& Psychiatry, 13, 314-319.

WILLIAMS, M. (1966). Memory disorders associated with electroconvulsive therapy. In C. M. Whitty \& O. L. Zangwill (Eds.), Amnesia (pp.134-149). London: Butterworths.

\section{NOTES}

1. We thank D. D. Dorfman for recommending this analysis

2. It should be noted that Haist et al. (1992), using a paradigm that superficially resembled ours, failed to find disproportionate sparing of recognition. However, whereas Haist et al. used a forced-choice recognition test followed by a confidence rating task, in our procedure criterion was directly manipulated. Our subjects used different criteria to make their recognition judgments; they did not rate their confidence after the fact.

(Manuscript received June 24, 1994; revision accepted for publication October 3, 1994.) 